\title{
Investigating the risky behavior of international tourists riding motorcycles in Bali
}

\author{
Dewa Made Priyantha Wedagama ${ }^{1,{ }^{*}}$ and Darren Wishart ${ }^{2}$ \\ ${ }^{1}$ Department of Civil Engineering, Universitas Udayana, Bukit Jimbaran Bali, Indonesia 80361 \\ ${ }^{2}$ CARRS-Q, Queensland University of Technology, Q 4059 Brisbane, Australia
}

\begin{abstract}
Motorcycle accidents and injuries in Bali have been highly occurred as to a cause of their predominance in urban transportation structures. While riding a motorcycle, a tourist eventually is obligated to his/ her own particular safety. Road safety analysts are concerned with accident risk faced by tourists because of a great possibility to be associated with a road accident while on vacation. This research investigated motorcycle riding behaviors and combined with a scope of psychosocial factors for example, sensation seeking, risky riding intentions and attitudes using international tourists riding motorcycles whilst on vacation in Bali as the respondents. Two models are constructed comprising of Principal Component Analysis (PCA) and Structural Equation Model (SEM). Predictors employed socio-demographic variables consisting exposure and years licensed, gender, age, education levels, and estimates of distance travelled. International tourists revealed a scope of purposes behind riding motorcycles in Bali, for example, for fun and feelings of freedom. This research discovered that male international tourists with sensation seeking will probably be taking part in traffic and speeding infringement in contrast with females. These study outcomes alongside the suggestions for tourists training and road safety campaign while on holiday in Bali are examined.
\end{abstract}

\section{Introduction}

Bali island is the most tourist destination in Indonesia and is heavily dependent on tourism. International and domestic travelers are approximate of 3.7 and 6.9 million people per year respectively visiting Bali [1]. Meanwhile, a motorcycle is highly used as a method of transport among tourists and local inhabitants to travel in Bali. In comparison to the total of motor vehicles registered in Bali, approximately $86 \%$ were motorcycles [1]. Moreover, the additional information shows that the quantity of yearly registered motorcycle increased by $11 \%$ [1].

The prevalence of motorcycles as a method for transport in Bali principally is because of its dependability in overcrowded traffic and on narrow motorways and the capability of motorcycles to get to isolated places of the urban and rural regions not generally accessed to by optional method of transport. Moreover, this method of transport is progressively

\footnotetext{
*Corresponding author: priyantha@civil.unud.ac.id
} 
typical for tourists in Bali because of different components related with transportation, for example, the obtainability and convenience of motorcycle rental and the undependability of the existing public transport. Similarly, motorcycles in other parts of Asia are a favored method of transportation for tourists because of lessened journey periods and the low expenditures linked to fuel utilization and rental [2].

Undesirably, a high rate of motorcycle accidents and injuries has been credited to their predominance in urban transportation structures in Bali. Any given traffic accident has the potential damage that is more significantly related to motorcycle riders and their pillions. Principally, this is because of an absence of safety offered by the auxiliary reliability of a motorcycle [3]. As expected, past traffic safety researches examined in Bali demonstrate that motorcycle rider essentially added to traffic accidents and fatalities[4-7].

While motorcycle accidents in Bali dominated with local people, and numerous tourists likewise utilize motorcycles as a method for transportation around the island. This is apparent by the various motorcycles rental offices went for giving rental motorcycles, mainly to tourists. Meanwhile, the risky riding behavior may exist for inexperienced motorcycle riding tourists. The safety of tourists riding a motorcycle may be of interest because the same number of tourists are frequently clueless of trip dangers they will confront while riding in new road traffic environment. Past study has recognized the outcomes related with tourists accidents while holidaying abroad particularly as to the injury and monetary effect in the tourists' nations of origin [8].

In endeavoring to comprehend better factors affecting motorcycle rider behavior and traffic accidents afterward, a past examination [9] have explored a scope of psychosocial factors impacting motorcycle rider behavior, for example, intentions, attitudes, aggression, and sensation seeking. A different investigation [10] has recommended that distinguishing and examining the impact of different motorcycle riders' perceptions is significant to creating and planning viable countermeasures to enhance motorcycle rider safety. It stays indistinct, however, the influence of the psychosocial variables on the intentions and behavior of motorcycle riding tourists on vacation. Considered Bali island as a prominent tourists destination as well as the expanding utilization of motorcycle as a method for transport by tourists, it is important to explore the influence of psychosocial variables on the behavior of international motorcycle riders. This aims to advise the change of strategies for the safety of international motorcycle riders in Bali.

Moreover, exploring the intentions of international motorcycle riders towards traffic safety especially Bali is vital. The consistency to traffic activity may control the influences of the safety of motorcycle rider, as well as other road users. Hence, this study motivates in building up an understanding of the impact of the psychosocial variables on the behavior of motorcycle riders on the road. Also, this study examines self-reported intentions of tourist motorcycle riders participated in behavior associated with speeding and traffic violations on streets.

\section{Methods}

This research shapes some portion of more extensive motorcycle safety to be considered in Bali, where by potential respondents were drawn closer on the road at areas frequented by motorcycle riders and requested to take an interest in a more extensive motorcycle study. Before getting an endorsement to take an interest, scientists disclosed to respondents the idea of the examination and guidelines guaranteeing classification and secrecy. After consenting to receive interest, respondents were furnished with an overview. A sum of 300 motorcycle riders who distinguished themselves as international tourists consented to take part and finish the survey. Because of missing information, the viable respondents incorporated into the examination were 279 (92.7\%) out of total 120 females and 159 
males. The range of age of the respondents was in between 16 and 70 years with the average age was 33 years, and the standard deviation was equal to 11 years.

Table 1. The questionnaire.

\begin{tabular}{|l|}
\multicolumn{1}{|c|}{ I. Riding experiences and socio-demographic characteristics } \\
\hline 1.a. Riding licence ownerships \\
\hline 1.b Education level \\
\hline 1.c Gender and Nationality \\
\hline 1.d Kilometers travelled \\
\hline 1.e Age \\
\hline
\end{tabular}

\section{Psychosocial influences on riding intentions}

2.a Measures on the intentions of risky riding (1: strongly disagree; 7: strongly agree)-eight items

2.b Measures on the influence of perceptions of family and friends-subjective norm (1: strongly disagree; 7: strongly agree)-four items.

2.c Measures on the influence of the people's perceptions that respondents ride with-specific subjective norm (1: strongly disagree; 7: strongly agree)-four items.

\section{Perceptions on riding a motorcycle}

3.a Measures on the propensity of riders for aggressive riding (1: never; 7: always)-seven items.

3.b Measures on the significance of motorcycle riding skills (1: not important at all; 7: very Important)-five questions.

3.c Measures on attitudes towards risky riding behaviors and traffic rule violations (1: strongly disagree; 7: strongly agree)-22 items.

3.d Reasons behind motorcycle riding a (1: not important at all; 7: very Important)-six questions.

3.e Measures on sensation seeking-eight items

The questionnaire was organized into three different subjects which consisting a total of 64 queries as shown in Table 1. The respondents were asked for giving a sign from 1 (strongly disagree) to 7 (strongly agree) on a 7-point Likert scale, contingent upon the study item. A concise explanation was provided to the respondents at each introduction of the questionnaire' segment to describe the foundation of the inquiries. The survey acquired information identifying with self-reported riding behavior and the perceptions of respondents, the tendency for aggressive riding, sensation seeking, risky riding intentions, and subjective and specific subjective norms. Also, items cover with riding experiences and socio-demographic characteristics of the respondents.

In relation to self-reported riding behavior and the perceptions of respondents, the respondents identified the significance of particular abilities on motorcycle riding and purposes on motorcycle riding from 1 (not important at all) to 7 (very important). Meanwhile, measures on sensation seeking utilized eight items scale of thrill-seeking. For example, a statement of I would enjoy riding a motorcycle on the road with no speed limit 
with scores extending from 1 (strongly disagree) to 7 (strongly agree). The tendency for aggressive riding utilized seven items with answer running from 1 (never) to 7 (always), for instance, a statement of Ridden especially close to the vehicle in front as a signal to its rider/ driver to go faster or get out of the way. Twenty-two statements were utilized to measure motorcycle rider attitudes towards unsafe riding behavior and traffic rule violations, for instance, It's ok to ride over the speed limit as long as you don't get caught. Items that demonstrated either relative of a person the respondents ride with would not need them to ride dangerously were utilized to measure subjective and particular subjective norms, for example, push myself and or the bike to the point where handling becomes unpredictable.

\section{Modelling results and analysis}

Table 2 shows all classifications for psychosocial and perceptions data in this research.

Table 2. Latent and observed variables-reliability analysis.

\begin{tabular}{|c|c|c|c|c|}
\hline \multirow{2}{*}{$\begin{array}{c}\text { Latent } \\
\text { variables }\end{array}$} & \multirow[b]{2}{*}{ Observed variables } & \multicolumn{3}{|c|}{ Reliability } \\
\hline & & $\begin{array}{l}\text { Loading } \\
\text { factors }\end{array}$ & $\begin{array}{l}\text { \%Variance } \\
\text { explained }\end{array}$ & $\begin{array}{c}\text { Cronbach's } \\
\text { Alpha }\end{array}$ \\
\hline \multirow{2}{*}{ Impression } & Q2.5 To impress others & 0.882 & \multirow{2}{*}{28.250} & \multirow{2}{*}{0.708} \\
\hline & Q2.4 Image & 0.828 & & \\
\hline \multirow{2}{*}{$\begin{array}{l}\text { Reasons for } \\
\text { riding }\end{array}$} & Q2.2 Enjoyment/fun & 0.823 & \multirow{2}{*}{34.447} & \multirow{2}{*}{0.760} \\
\hline & Q2.1 No pressures/ feeling of freedom & 0.766 & & \\
\hline \multirow{3}{*}{$\begin{array}{l}\text { Risky riding } \\
\text { intentions } \\
\text { speed } \\
\text { (likely to do } \\
\text { in } \\
\text { the next } 12 \\
\text { months) }\end{array}$} & $\begin{array}{l}\text { Q9.8 Ride at } 50 \mathrm{kph} \text { over the speed limit } \\
\text { in the next } 12 \text { months }\end{array}$ & 0.717 & \multirow{3}{*}{30.164} & \multirow{3}{*}{0.775} \\
\hline & $\begin{array}{l}\text { Q9.7 Race other riders in the next } 12 \\
\text { months }\end{array}$ & 0.841 & & \\
\hline & $\begin{array}{l}\text { Q9.6 Try to break my own speed record } \\
\text { in the next } 12 \text { months }\end{array}$ & 0.831 & & \\
\hline \multirow{6}{*}{$\begin{array}{l}\text { Sensation } \\
\text { seeking }\end{array}$} & $\begin{array}{l}\text { Q4.7 I like to raise my adrenaline levels } \\
\text { while riding }\end{array}$ & 0.807 & \multirow{6}{*}{52.534} & \multirow{6}{*}{0.894} \\
\hline & Q4.5 I enjoy cornering as fast as I can & 0.784 & & \\
\hline & Q4.4 I get a real thrill out of riding fast & 0.867 & & \\
\hline & Q4.3 I enjoy taking risks on my bike & 0.706 & & \\
\hline & $\begin{array}{l}\text { Q4.2 I enjoy the sensation of accelerating } \\
\text { rapidly }\end{array}$ & 0.871 & & \\
\hline & $\begin{array}{l}\text { Q4.1 I would enjoy riding on a road with } \\
\text { no speed limit }\end{array}$ & 0.776 & & \\
\hline
\end{tabular}


The Principal Component Analysis (PCA) was conducted using numerous measures including rotated principal component loadings and reliability values greater than 0.7 , eigenvalues more than 1 and $20 \%$ or more explained variances [11]. A Cronbach's alpha is used to estimate data reliability. The alpha is used to evaluate unidirectional of a single latent construct in the form of a coefficient of consistency which indicating the goodness of fit of a variable or a factor.

The relationships between latent and observed variables shown in Table 2 are to be tested to construct the hypothesized models as follows:

$\mathrm{H}_{1}$ : The intentions of risky riding behavior are influenced with the perception of international motorcycle riders.

$\mathrm{H}_{2}$ : The perceptions (fun riding, impression and sensation seeking) of international motorcycle riders are affected by socio-demographic characteristics.

$\mathrm{H}_{3}$ : The intentions of international motorcycle riders on riding motorcycles are influenced with socio-demographic characteristics.

Four latent variables were obtained in the model as shown in Table 2. Also, Table 2 presents factors that only fulfill the criteria required for PCA. Four constructs included impression, reasons for riding, intentions to speed and sensation seeking to clarify $28.25 \%$, $34.45 \%, 30.16 \%$, and $52.53 \%$ of the component variances respectively. Sensation seeking contained six items with factor loadings in between 0.77 and 0.87 . In addition, a high level of internal consistency was achieved which shown by a solid general Cronbach' alpha greater than 0.89 . Meanwhile, risky riding intentions to speeding included three items with factor loadings in between 0.71 and 0.84 and a Cronbach Alpha of 0.77. Purposes behind riding motorcycles contained two items with factor loadings of 0.76 and 0.82 and Cronbach Alpha of 0.76 . The variable marked impression stacked with two things of 0.82 and 0.88 and exhibited a Cronbach Alpha of 0.7 .

As appeared in Fig. 1, the model was constructed describing the correlations between observed and latent variables and among latent variables. The figure demonstrates threelevel influential ways from individual characteristics factors to four inert factors of purposes behind riding, impression, and sensation seeking and intentions to speed. The endogenous factors for this structural equation model, therefore, consisted of the latent constructs of impression, reasons for riding, intentions to speed and sensation seeking. Meanwhile, the exogenous factors were education level, ages, yearly kilometers traveled (kmsTravelled) and years licensed.

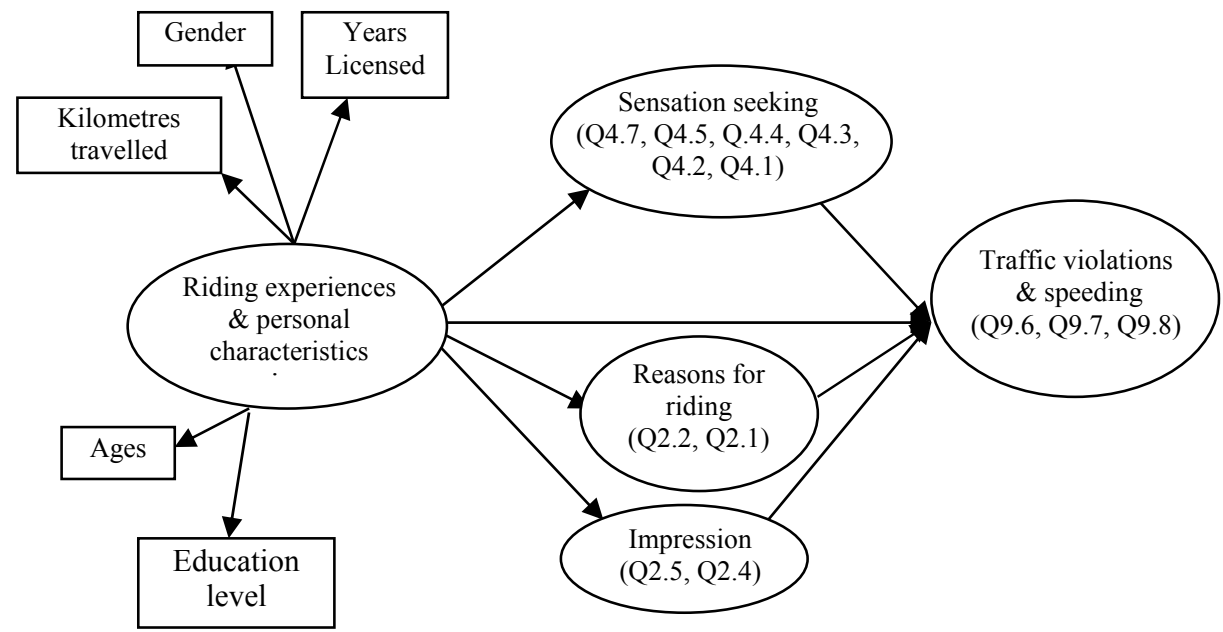

Fig.1. International tourist behaviors-the conceptual model. 
Two observed variables of Q2.2 (fun/ enjoyment) and Q2.1 (no pressures/ feelings of freedom) dictated the explanations behind motorcycle riding. Two observed variables of Q2.5 (to impress others) and Q2.4 (image) was used to construct a latent variable of the impression.

Table 3. Model validation.

\begin{tabular}{|l|c|c|c|c|c|c|c|c|c|c|}
\hline $\begin{array}{l}\text { Measures } \\
\text { of fit }\end{array}$ & NFI & AGFI & RMSEA & GFI & PNFI & CFI & df & $\chi^{2}$ & $\chi^{2} / \mathbf{d f}$ & p-value \\
\hline Model & 0.86 & 0.86 & 0.07 & 0.90 & 0.68 & 0.92 & 121 & 266.02 & 2.20 & 0.00 \\
\hline
\end{tabular}

Table 4. Regression weight of international tourists model.

\begin{tabular}{|l|l|l|l|}
\hline \multicolumn{2}{|c|}{ The relationships among variables } & Estimate(s) \\
\hline Sensation seeking & $\leftarrow$ & Gender & $1.029^{* *}$ \\
\hline Sensation seeking & $\leftarrow$ & $\begin{array}{l}\text { Riding license } \\
\text { ownership }\end{array}$ & $-0.288^{* *}$ \\
\hline Sensation seeking & $\leftarrow$ & Ages & $-0.446^{* *}$ \\
\hline Speeding & $\leftarrow$ & Sensation seeking & $0.370^{* *}$ \\
\hline Reason for riding & $\leftarrow$ & Gender & $0.475^{*}$ \\
\hline Speeding & $\leftarrow$ & Gender & $0.384^{*}$ \\
\hline Impression & $\leftarrow$ & Gender & $0.306^{*}$ \\
\hline Impression & $\leftarrow$ & Ages & $0.213^{*}$ \\
\hline Impression & $\leftarrow$ & Kilometres travelled & $0.119^{*}$ \\
\hline $\begin{array}{l}\text { Ride at 50kph over speed limit in the next 12 } \\
\text { months (Q9.8) }\end{array}$ & $\leftarrow$ & Speeding & $0.799^{* *}$ \\
\hline Race other riders in the next 12 months (Q9.7) & $\leftarrow$ & Speeding & $0.791^{* *}$ \\
\hline $\begin{array}{l}\text { I like to raise my adrenaline levels while riding } \\
\text { Q4.7) }\end{array}$ & $\leftarrow$ & Sensation seeking & $0.966^{* *}$ \\
\hline I enjoy cornering as fast as I can (Q4.5) & $\leftarrow$ & Sensation seeking & $0.791^{* *}$ \\
\hline I get a real thrill out of riding fast (Q4.4) & $\leftarrow$ & Sensation seeking & $1.154^{* *}$ \\
\hline I enjoy taking risks on my bike (Q4.3) & $\leftarrow$ & Sensation seeking & $0.622^{* *}$ \\
\hline $\begin{array}{l}\text { I enjoy the sensation of accelerating rapidly } \\
\text { (Q4.2) }\end{array}$ & $\leftarrow$ & Sensation seeking & $1.127^{* *}$ \\
\hline To impress others (Q2.5) & $\leftarrow$ & Impression & $2.244^{* *}$ \\
\hline Feeling of freedom/ no pressures (Q2.1) & $\leftarrow$ & Reason for riding & $0.838^{*}$ \\
\hline
\end{tabular}

* significantly different from zero at the 0.05 level, ** significantly different from zero at the 0.001 level. 
Six observed variables consisted of Q4.7 (I like to raise my adrenaline levels while riding), Q4.5 (I enjoy cornering as fast as I can), Q4.4 (I get a real thrill out of riding fast), Q4.3 (I enjoy taking risks on my bike), Q4.2 (I enjoy the sensation of accelerating rapidly), and Q4.1 (I would appreciate riding on a road with no speed limit) were employed to construct a latent variable of sensation seeking. Likewise, three observed variables comprised of Q9.8 (ride at $50 \mathrm{kph}$ over the speed limit in the next 12 months), Q9.7 (race other riders in the next 12 months), and Q9.6 (try to break my own speed record in the next 12 months) were used as dependent variables and to construct a latent variable of speeding.

This study utilizes model validation indicators of previous research [12]. Table 3 shows the goodness of fit for the model developed for this study. A few measures comprising of NFI, CFI, GFI excluding AGFI/df, RMSEA, and PNFI showed that the constructed models are statistically satisfactory.

The connection between the model factors and the estimates are exhibited in Table 4. Table 4 demonstrates that two hypotheses presumptions $\left(\mathrm{H}_{1}\right.$ and $\left.\mathrm{H}_{2}\right)$ for the constructed model have been statistically accepted. All the more particularly, the SEM clarifies that motorcycle riders' intentions to speed and traffic offenses are affected by their image and impressing others, their sensation seeking, explanations behind riding and demographic variables. Table 4 uncovers that sensation seeking (predicted value $=0.37$ ) and gender (predicted value $=0.384$ ) are two significant factors that impact international tourists to speed while riding motorcycles. Following this finding, past examination [13] reasoned that sensation is seeking for fundamentally connected with a negative attitude towards traffic safety, for example, speeding and traffic violations.

All the more particularly, male riders in contrast with female riders will probably take part in sensation seeking and intentions to take part in traffic offenses. Furthermore, gender influences international tourists on riding motorcycles for the feeling of freedom and enjoyment, to impress others and speeding. This infers male international tourists who ride a motorcycle in Bali do as such for the sense of freedom, impress others, and will probably speed in contrast with females. The outcomes likewise show that older and more experienced motorcycle riders are less inclined to report needing to participate in behaviors related to sensation seeking. A past report [14] likewise found that age and riding experiences were connected to riders' decision to as being most imperative for motorcyclist safety.

The number of years licensed is altogether adversely identified with sensation seeking for demonstrating that international tourists with riding experience estimated by years licensed are less likely to report significant amounts of sensation seeking. Despite that, riding exposure is determined as yearly kilometers traveled and was altogether identified with an impression or impressing others.

\section{Conclusions}

The study objectives to examine the influence of psychosocial variables on international tourists' riding behavior while on vacation is because of the high number of traffic accidents involving motorcycle riders in Bali as a prominent tourist destination. The study found that sensation seeking in a blend with various demographic characteristics, for example, age, gender, and years licensed, resulted in a feeling of freedoms and fun riding which may influence unsafe riding behaviors such as violating traffic rules and speeding.

Specifically, the study demonstrated male tourists riding motorcycles in Bali in contrast to females were more involved in sensation seeking and had a tendency to participate in speeding and traffic rule violations. Older and more experienced male motorcycle riders while on vacation in Bali however, will probably attempt to have safe riding behaviors. In other words, the study confirms that young male tourists riding motorcycles have higher 
potential risk than older ones. It remains unclear, however, whether the risky riding behavior is because tourists encountered diverse traditions and road conditions or are because of riding practices in their own country. Having considered the potential risk in connection with international motorcycle riders in Bali, this study suggests a significant effect on tourist campaign and education on motorcycle safety riding.

In any case, similar to all examination various restrictions must be considered on the results of this study. The data is self-reported and experiences average constraints related to information of a self-report nature. Besides, while this investigation already created measures on the study of motorcycle safety riding, the relevant items in the questionnaire with specific circumstances and experience of motorcycle riding behavior in Bali stays indistinct. The study suggests that the improvement of the scope of research that particularly identifies with conditions and behaviors regularly experienced in Bali. At last, future study particularly exploring the requirements related to international motorcycle accidents and rider behavior could give different understanding into other contributing variables to illuminate educational and tourist traffic safety campaigns.

\section{References}

1. Statistics of Bali Province, Bali in Figures (Bali Provincial Government, 2017)

2. A.K.I. Sheikh, R.S.R. Umar, M. Habsah, H. Kassim, M. Stevenson, A. Hariza, Traffic Inj. Prev. 7 (2006)

3. B. Watson, D. Wishart, T. Christie, Canberra motorcycle apparel observation study (NRMA Road Safety Trust, 2008)

4. D.M.P. Wedagama, IATSS Research 33, 2 (2009)

5. D.M.P. Wedagama, D. Dissanayake, J. of EASTS. 8 (2010)

6. N. Budiartha R.M, J. of Society for Transp. and Traff. Studies 5, 2 (2015)

7. P.A. Suthanaya, Int. J. Engr. Res. Africa 19 (2016)

8. M. Sherry, M. Mossallam, M. Mulligan, A. Hyder, D. Bishai, Injury Prevention 21 (E1) (2015)

9. C. Seabra, S. Dolnicar, J.L. Abrantes, E. Kastenholz, Tourism Man. 36 (2013)

10. P. Hongsranagon, T. Khompratya, S. Hongpukdee, P. Havanond, N. Deelertyuenyong, IATSS Research 35 (2011)

11. D. Hooper, J. Coughlan, M. Mullen, Electronic J. of Buss. Res. Methods 6, 1 (2008)

12. K. Schermelleh-Engel, H. Moosbrugger, MPR-Online 8, 2 (2003)

13. P. Ulleberg, T. Rundmo, Safety Science 41 (2003)

14. A. Weissenfeld, M. Baldock, T.P. Hutchinson, Proc. of the Australasian College of Road Safety Conference (2013) 